\title{
Sentimientos morales y políticos en la formación ciudadana en Colombia: atributos y estigmas ${ }^{1}$
}

\section{Moral and political feelings in civic education in Colombia: attributes and stigmas}

\author{
Marieta Quintero Mejía ${ }^{2}$ \\ Jennifer Mateus Malaver ${ }^{3}$
}

Resumen

Los procesos de formación ciudadana se han centrado en el fortalecimiento de los razonamientos y justificaciones, propios de la vía cognitiva de la moral, lo que ha llevado a situar los sentimientos morales y políticos en un lugar restringido. Esto permite comprender, en buena medida, las razones por las cuales dichos sentimientos no han sido valorados como vitales para nuestra vida política y moral. Por ello, la empatía, la solidaridad, la indignación, entre otros sentimientos, han sido despojados de su naturaleza intersubjetiva y relegados al campo de lo irracional. Precisamente, en este artículo se presentan algunos atributos y estigmas de los sentimientos en los procesos de formación cívica. Para ello, se analizan algunos textos escolares (del año 1800) y se exponen los resultados de entrevistas a miembros de instituciones educativas afectadas por el conflicto armado colombiano. Consideramos que el sentido de lo público, los procesos de socialización y las formas de acción colectiva están motivados, de alguna manera, por sentimientos que generan rechazo/indiferencia ante situaciones de vulneración de derechos.

\section{Palabras clave}

Sentimientos morales y políticos, indignación, vergüenza, repugnancia, derechos, resistencia.

\section{Abstract}

The processes of civic education have been focused on the strengthening of the cognitive path of morals, which has led to locating moral and political feelings in a restricted place. This allows us to understand, to a considerable extent, the reasons for which we have valued these feelings as vital for our political and moral life. Because of this, feelings such as empathy, solidarity, indignation, among others, have been stripped of their intersubjective nature and been pushed back into the field of irrationality. In order to account for this, this article presents some attributes and stigmas of feelings in the process of civic education. To this aim, scholarly texts are analysed ( 1800 , to be exact), and the results of interviews with members of educational institutions in four Colombian departments affected by the Colombian armed conflict are given. We consider that the meaning of the public, the processes of socialisation, subjectivity, as well as our forms of collective action, are motivated, in some way, by feelings which trigger rejection/indifference; resistance/apathy when faced with situations where our rights are violated.

\section{Keywords}

Moral and political feelings, indignation, shame, repulsion, rights, resistance

Artículo recibido el 20 de septiembre de 2013 y aprobado el 14 de febrero de 2014

1 El presente artículo es producto de la investigación "Programas de formación y evaluación de competencias ciudadanas en zonas de conflicto interno colombiano: análisis de impacto en los aprendizajes ciudadanos", financiado por ICFES y Colciencias. Este proyecto (Código N 113051828140) fue ejecutado por el grupo de investigación MORALIA de la Universidad Distrital Francisco José de Caldas y el grupo Perspectivas Políticas, Éticas y Morales de la Niñez y la Juventud de CINDE.

2 Universidad Distrital, Bogotá, Colombia. marietaqmg@gmail.com

3 Universidad Javeriana, Bogotá, Colombia. Jennifera88_19@hotmail.com 
Universidad Pedagógica Nacional

Facultad de Humanidades

En las tradiciones cívicas - liberalismo, comunitarismo y republicanismo-, los sentimientos son objeto de estudio por un número reducido de teóricos, entre otros, tenemos a Hutcheson (1999), Hume (1989; 1990; 1992; 2006), Smith (1996), Strawmson (1995), Heller (2004), Nussbaum (1995, 1997,2003, 2006, 2008) y Honneth $(1997,2009,2010,2011)$. Mientras que en el campo de la formación ciudadana encontramos una mínima fundamentación, por no decir nula. Es preciso señalar que en esta formación han prevalecido asuntos relacionados con:

- Conocimientos: ¿Qué debo saber o conocer?

- Acciones: ¿Qué decisiones debo tomar? Y ¿qué debo hacer?

- Actitudes: ¿Qué tipo de actuaciones o realizaciones esperamos de un sujeto? y ¿cuáles son las disposiciones que tenemos para hacer cierta clase de juicios o para actuar de cierta manera?

También ha predominado el carácter cognitivo de la moral, orientado a establecer una interacción entre estructuras propias de los sujetos (cognitivas) con las del medio social. Lo anterior explica las razones de orden conceptual y empírico que han llevado a que, en procesos de formación ciudadana, exista privilegio por la vía cognitiva de la justicia, y, escasamente, se reconozcan los sentimientos morales y políticos como fundantes en procesos de formación ciudadana.

El posicionamiento cognitivo de la justicia en asuntos de ciudadanía tiene su génesis en la tradición de la filosofía moral griega (Aristóteles y Platón), sus fundamentos se ubican en la tradición moderna (Kant, 1785/1989; y Rousseau, 1762/1993) y, sus más destacadas evidencias empíricas, en el mundo contemporáneo (Piaget, 1977; Kohlberg, 1992).

\section{Gramática de los sentimientos morales y políticos: algunos atributos}

Los fundamentos de las éticas basadas en los sentimientos morales, en buena medida, se oponen a las tesis de las éticas racionalistas. La reacción más fuerte está presente en Hume (1990) quien sostiene que los sentimientos - simpatía - nos mueven a la vida moral y no la razón. Por ello, la toma de decisiones y la realización de acciones morales son expresiones del placer y de la alegría que nos propicia la búsqueda de la felicidad de la humanidad. Podríamos decir, entonces, que las acciones morales y políticas no dependen de la razón, sino de los deseos, pasiones y afectos de los seres humanos. Esto no significa, siguiendo los postulados de Hume, que no podamos razonar acerca de las pasiones.

Sin embargo, no podemos limitar la arquitectura filosófica de los sentimientos a las tensiones entre razón y emoción, aunque estas discusiones han dado lugar a las más fructíferas aclaraciones sobre los atributos de los sentimientos. En su lugar, destacamos la riqueza en los argumentos acerca de su carácter intersubjetivo y relacional. Esto significa que los ciudadanos adquirimos un sentido de lo público cuando rechazamos -indignación - todas aquellas acciones egoístas que conducen a la miseria y sentimos felicidad por aquellas acciones que propician un mayor bien (Hume, 1989). El interés por el bien común es señal de la búsqueda de una vida buena y digna.

Para alcanzar este bien común, autores como Hutcheson (1999), considerado el primer exponente de la teoría de los sentimientos morales, propusieron la benevolencia como el sentimiento a través del cual el sujeto expresa y actúa para alcanzar el bien público. Dicho sentimiento por su naturaleza social exige, a partir de lo expuesto por Hutcheson, poner al margen cualquier inclinación personal. Siguiendo a los autores en mención, podríamos indicar que otro atributo de los sentimientos es constituirse en guía para nuestras acciones y prácticas ciudadanas. También se destaca su carácter intersubjetivo, pues se espera que los sujetos morales y políticos actúen con simpatía y benevolencia frente a determinadas experiencias que nos sitúan en condición de fragilidad.

Asimismo, los sentimientos expresan la vulnerabilidad y el rechazo que sentimos frente a cualquier situación que exprese un daño moral. En otras palabras, las preferencias, reprobaciones o la misma 
indiferencia de nuestros congéneres frente a infortunios o situaciones de vulneración de derechos erosionan o exaltan nuestros sentimientos. Por ello, sentimientos como la vergüenza y la indignación están estrechamente relacionados con situaciones de vulnerabilidad en las cuales reconocemos los perjuicios vividos y en la que nos sentimos afligidos por la suerte acaecida (propia o ajena). Además de esta dimensión ética y política, los sentimientos enunciados nos recuerdan nuestra condición de seres frágiles.

Para Nussbaum (2006) sentirnos frágiles o reconocer que no somos dioses hace posible que entendamos los vínculos que nos unen con los otros. Carecer de esta noción de fragilidad o estar expuesto a situaciones de contingencia nos lleva a tener un grado de autosuficiencia y a sentirnos inmunes, lo que hace que extirpemos todas aquellas emociones vinculantes. Esta ausencia de sabiduría práctica puede llevar a que los ciudadanos le demos la espalda a cualquier tipo de experiencia en la cual aparezca la indefensión. Incluso, nos puede llevar a suponer que los conflictos no hacen parte de nuestras vidas, pues serían desastres extraordinarios a los que no estamos expuestos, ni dispuestos a sensibilizarnos. Lo cual conduciría a que el ciudadano no actúe ni exija derechos ante los infortunios vividos por los otros en la vida pública —indiferencia moral y política一.

Podemos señalar, entonces, que existen sentimientos reactivos o negativos - vergüenza e indignación-, vinculados a experiencias de vulneración, los cuales ocupan un lugar central en nuestra vida con los otros. La noción "negativo" no ha de entenderse como detenernos o "paralizarnos" ante la ejecución o puesta en marcha de acciones jurídicas. Son sentimientos negativos en tanto expresan violaciones que requieren, justamente, de la existencia de normas y leyes jurídicas que hagan posible la reparación y restauración de los daños causados. Los sentimientos reactivos también señalan que las demandas políticas no se quedan en el plano jurídico, dan lugar a la justicia anamnética en la cual los derechos de las victimas no perecen. Esta memoria ante los hechos de injustica se levanta como exigencia de justicia ante los sufrimientos de las víctimas (Reyes Mate, 1991).

Los sentimientos de vergüenza e indignación en la sociedad civil son motores, entre otros, de dos acciones políticas complementarias. Por un lado, dan a lugar a luchas sociales y demandan imputación, resistencia y desobediencia civil ante situaciones de injusticia. Del otro, justifican las normas legales en tanto invocan sanciones penales, pero así mismo restauración de daños y perjuicios. Los sentimientos morales de indignación, vergüenza y culpa, entre otros, son respuesta al grado de vulnerabilidad al que podemos estar expuestos. Así, estas dos acciones políticas provocan el fortalecimiento de una justicia dinámica (Heller, 2004), orientada a afirmar los vínculos entre normas con los contextos sociales y políticos en los cuales suceden las fracturas morales y políticas.

Esta justicia dinámica muestra que si bien las relaciones entre grupos miembros de las sociedad, así como los cambios económicos y políticos en las sociedades, exigen contar con una justicia con equidad, no es suficiente, pues en nuestra praxis van apareciendo otros modos de injusticia, desigualdad y de vulneración de derechos. Los modos de imputación, reivindicación y asociación de los colectivos exponen las razones y las creencias sobre las cuales se deben hacer los cambios a la justicia: razones y creencias solventadas en criterios cognitivos, pero también emocionales. Con esta gramática de los sentimientos, se ilustran los vínculos que se establecen entre éstos con los derechos, la política y la moral.

\section{Estigmas acerca de los sentimientos en la formación ciudadana}

Uno de los estigmas que se busca objetar es la opinión generalizada de que los sentimientos no son fuente adecuada para la toma de decisiones, por su carácter de irracionalidad. Con este argumento se desconoce que los sentimientos expresan creencias y generan reacciones. Por lo tanto, en estos encontramos un carácter comunicativo y performativo. Precisamente, Nussbaum (2006) indica que los 
Universidad Pedagógica Nacional

Facultad de Humanidades

sentimientos hacen parte de las experiencias humanas porque ellas contienen nuestras creencias. Al respecto, señala la autora, el mismo Aristóteles en Retórica da consejos a jóvenes oradores acerca de cómo crear emociones en sus auditorios teniendo en cuenta el cúmulo de creencias que estos tienen acerca de la vida y en sus vínculos con los otros. Por ello, si un orador quiere generar temor debe convencer al auditorio de que ocurrirán cosas malas y que no se pueden impedir tales sucesos. Así mismo, si busca generar enojo debe convencerlos de que han ocasionado un perjuicio de forma voluntaria $e$ injusta (Nussbaum, 2006, p. 40). Si la retórica, que estudia y utiliza el lenguaje a partir de un sistema de reglas y de una estructura lógica y argumentativa, crea emociones en el auditorio podemos afirmar que estas no son irracionales.

$\mathrm{Al}$ respecto, la filósofa sostiene que las emociones no deben ser consideradas "energías o impulsos de carácter animal sin conexión con nuestros pensamientos"; por el contrario, son "levantamientos" de carácter cognitivo, los cuales están influenciados por el discernimiento que tenemos sobre los objetos y circunstancias que nos rodean. Por ello, los sentimientos constituyen una parte fundamental en nuestro sistema de razonamiento, lo que indica que cumplen con dos condiciones básicas: 1) son de carácter relacional, lo que significa que nos vinculan con otros, organizando los juicios y percepciones que tenemos acerca de ellos; 2) son intencionales, es decir, que dependen de la forma como pensamos e interpretamos nuestro entorno. La posibilidad de definir los sentimientos muestra las creencias que tenemos acerca de estos. A manera de ilustración, para definir sentimientos reactivos o negativos temor y pena- necesitamos incorporar las creencias que tenemos acerca de estos, de lo contrario no podríamos identificarlos como negativos, es decir, estarían desprovistos de la noción del daño causado: "El temor, por ejemplo involucra la creencia de que algo malo ocurra en el futuro. La ira, la creencia de un daño infringido injustamente. La pena requiere la creencia en el sufrimiento significativo de otra persona" (Nussbaum, 2006, pp. 41-42).
Para Nussbaum, otro estigma frecuentemente utilizado para despojar a los sentimientos de sus atributos es situarlos en la estructura de lo débil asociándolos, por lo general, a la figura de lo femenino. A juicio de la filósofa feminista Guerra (2012), los sentimientos morales, más que otros temas, poseen connotaciones sexistas. Indica la autora que desde los estoicos hasta Kant, los sentimientos que oscurecen, distorsionan y arruinan el juicio son propios de la vida de las mujeres. Por ello, a las mujeres se les ha imputado inferioridad racional —Kant, 1785/1994; Piaget, 1977; Kohlberg, 1984-. Llama la atención que los atributos de sentimientos relacionados con el afecto, lo maternal, filial, conyugal y comunitario en asuntos de ciudadanía estén arrojados en la esfera de la irracionalidad cuando son la base para la acción política.

Otro estigma señalado por Nussbaum se relaciona con la idea generalizada de que los sentimientos se restringen a los lazos o apegos con las personas más cercanas a nuestro círculo ético: "Las emociones siempre permanecen cerca del hogar y contienen, por así decirlo, una referencia de primera persona" (Nussbaum, 2006, p. 92). Esta cita explica por qué los sentimientos han sido considerados por filósofos y ciudadanos como fuerzas ciegas sin relación con círculos éticos amplios y, por lo tanto, sin ningún valor político. Una consecuencia de lo expuesto es suprimir o excluir los sentimientos de la vida pública y arrojarlos a la esfera de lo íntimo. En oposición a este argumento, Nussbaum señala su carácter intencional en la vida con los otros. Por ello, cuando expresamos un sentimiento lo asociamos a contextos, personas, situaciones, entre otros, independientemente de que estos se desplieguen en las esferas de lo privado o lo público, de lo contrario careceríamos de capacidad para identificarlas y, con ello, orientar nuestros planos de acción individual y colectiva.

Estas acciones pueden estar orientadas al reconocimiento del sujeto moral y político en las esferas del amor, la ley y la solidaridad. También asociadas a modos de menosprecio en las esferas mencionadas, lo que daría lugar al menosprecio, la injusticia y la 
insolidaridad. Las luchas por el reconocimiento ante situaciones de menosprecio en las esferas mencionadas son generadoras, justamente, de los conflictos sociales (Honneth, 1997, p. 211)

\section{Metodología}

En su naturaleza cualitativa este estudio se centró en el análisis de narrativas acerca de los sentimientos morales y políticos presentes en textos escolares de formación ciudadana en el periodo de 1800, entre los cuales están la Educación de la infancia, lecciones de moral y urbanidad para la infancia (1846) y Catecismo o instrucción popular (1820). En el periodo actual, se analizaron enunciados de niños, niñas, jóvenes, maestros y padres de familia acerca de los atributos y estigmas que tienen de los sentimientos en procesos de formación ciudadana. Estas dos fuentes fueron analizadas en su naturaleza discursiva, pues revelan la trama que ha configurado históricamente nuestras creencias. Por ello, esta trama, siguiendo a Ricoeur (2003), nos indica los vínculos y discontinuidades entre el pasado y el presente. En otras palabras, esta trama señala el devenir o la sucesión de generaciones cuya relación temporal da lugar a comprender continuidades, rupturas, revelaciones, tensiones, entre otros. Esta sucesión de generaciones, que no ha de entenderse como una lógica, permite, desde el anclaje temporal, comprender cómo se han construido los vínculos entre los agentes históricos y, con ello, comprender cómo se ha erigido la "historicidad pública" en relación con asuntos referidos a la formación ciudadana. En palabras de Ricoeur, se trata de la llegada incesante de nuevos portadores de cultura y de la partida continua de otros portadores. Asimismo, esta sucesión de generaciones se entiende como la presencia de la tradición y la innovación de una cultura.

\section{Estrategia de recolección y sistematización de la información}

Tanto los atributos como los estigmas acerca de los sentimientos en la formación ciudadana, asociados a situaciones de orden social, cultural y educativo, fueron interpretados a partir de dos estrategias metodológicas. En la primera tenemos archivos de textos escolares del año 1800, los cuales fueron asumidos, siguiendo a Ricoeur (2003), como narrativas de generaciones y fuentes de enunciación y no como cúmulo de documentos. Estos archivos como relatos, en palabras de Ricoeur, dieron cuenta de los acontecimientos, marcas, huellas y vestigios. Estos fueron objeto de interrogación para hacer posible la construcción de la memoria colectiva, la narración social y el significado del pasado en relación con nuestra formación ciudadana. Entre las fuentes analizadas tenemos: Los principios de legislación universal y legislación penal, (Bentham, 1816); Catecismo o instrucción popular (Fernández De Sotomayor, 1820); Educación de la infancia, lecciones de moral, virtud y urbanidad (1846); Catecismo republicano, instrucción popular, (Pinzón, Cerbeleón, 1865).

La segunda estrategia consistió en interpretar, en el periodo presente, los enunciados de niños, niñas, jóvenes y maestros acerca de los sentimientos en dicha formación; miembros de comunidades educativas situadas en contextos afectados por el conflicto interno colombiano. Estas huellas narrativas, en el sentido de Ricoeur (2003), contienen las prácticas discursivas a partir de las cuales podemos "ensanchar" la memoria colectiva acerca del lugar que han tenido en nuestra formación ciudadana los sentimientos morales y políticos. El proyecto se realizó en 16 instituciones educativas ubicadas en los departamentos de Meta, Cundinamarca, Atlántico y Bolívar. En total fueron 1200 estudiantes, 502 maestros y 502 padres de familia.

En la propuesta de sistematización se siguieron los siguientes momentos: ${ }^{4}$

Momento 1. Registro de codificación. El tema, problema y/o los objetivos de investigación orientaron la estrategia de recolección de información narrativa. Como problema y objetivos de investiga-

4 Este instrumento fue validado en la investigación publicada: Narraciones, memoria y ciudadanía. Desplazamiento forzado" (2008). Adicionalmente ha sido utilizada en investigaciones para optar por el título de pregrado, maestría y doctorado. Su publicación se encuentra en el libro Justificaciones y narraciones: orientaciones teóricas e investigativas, que se halla en prensa en la Universidad Distrital (2013). 
Universidad Pedagógica Nacional

Facultad de Humanidades

ción se buscó comprender los atributos y estigmas acerca de los sentimientos morales y políticos en procesos de formación ciudadana.

Momento 2. Nivel textual. Pre-concepción de la trama narrativa. Constituida por una red que contenía aspectos referenciales entendidos como informaciones acerca de los acontecimientos, las acciones y/o experiencias. En este nivel textual identificamos tres tipos de referencias encargadas de otorgar el carácter de inteligibilidad a la narrativa: hechos, temporalidades y espacialidades.

Momento 3. Nivel contextual de la trama narrativa. En este momento el análisis se centró en la fuerza narrativa la cual se entendió como el uso comunicativo y/o expresivo empleado por el sujeto de la enunciación para referirse a lo que con "el lenguaje hace" y a "lo que hace con lo que dice".

Momento 4: Nivel metatextual de la reconfiguración de la trama narrativa. Significó "una nueva lectura" de la trama de la narrativa resultado de: a) la interpretación en cada una de los dos anteriores momentos (preconfiguración y configuración de la narración); b) el diálogo con otras voces proveniente de otros actores, sujetos y textos de la enunciación, como de horizontes de referencia teórica.

\section{Resultados}

El desarrollo de esta investigación permitió establecer vínculos entre sentimientos morales con las esferas del derecho, la ética y la política. Asimismo, permitió mostrar que estos atributos quedan menguados y cooptados en proceso de formación ciudadana. Inicialmente, presentamos los hallazgos en narrativas de textos escolares, posteriormente los enunciados proferidos por los niños, niñas, jóvenes, maestros y padres de familiar.

Narrativas de textos escolares acerca de la gramática de los sentimientos morales y políticos. El vínculo entre sentimientos y restablecimiento de derechos se hizo presente en el texto de Catecismo o instrucción popular escrito en 1814 y publicado en 1820 por Juan Fernández de Sotomayor. Este pensador, además de redactar esta obra, fungió como cura, rector, vicario y juez eclesiástico de la ciudad de Mompox. Este Catecismo estimuló, sin rodeos y apelando a una retórica democrática, el sentimiento de indignación para promover prácticas de resistencia, rebeldía e insurgencia contra la corona española (Fernández de Sotomayor, 1814/1820): ${ }^{5}$

P. Y la conquista no es un motivo de justicia para dominar á la América?

R. La conquista no es otra cosa que el derecho que dá la fuerza contra el debil, como el que tiene un ladron, que con mano armada y sin otro antecedente que el de quitar lo ageno, acomete á su legítimo dueño, que, ó no se resiste, ó le opone una resistencia débil. Los conquistados así como el que ha sido robado pueden y deben recobrar sus derechos luego que se ven libres de la fuerza ó pueden oponerle otra superior.

P. Que derechos son estos que pueden recobrar los conquistados?

R. Los mismos que gozaban antes de la conquista: la libertad é independencia del conquistador. (pp. 4-5)

En la obra de Fernández de Sotomayor encontramos que los asuntos de la ciudadanía fueron enseñados a partir de la tensión entre libertad y opresión; ilustración y barbarie. A lo largo del texto también se sitúa el interés por enseñar los prejuicios y estereotipos que tenían los españoles contra "la república de los indios" o habitantes del Nuevo Reino de Granada. Los estigmas hacia nuestros antepasados (seres inferiores, ignorantes, bárbaros, miserables, débiles, oprimidos, entre otros.) se asociaban a la falsa idea de que poseían una condición natural que los llevaba a estar dominados por los sentimientos de enojo, culpa e ira. Para contrarrestar esta condición precaria, los españoles, representados por miembros de la Iglesia, propusieron fortalecer el sentimiento de compasión hacia esta población. Este sentimiento se asoció con prácticas de caridad y protección hacia quienes fueron considerados "de la más baja y humilde condición”. Estos sentimien-

5 La ortografía es propia del texto original. 
tos fortalecieron una estructura de subordinación centrada en el dominio de todos aquellos sentimientos que expresaran imputación o reclamación de derechos.

Si bien el texto de Fernández de Sotomayor fue objeto de repudio por parte de la corona, pues animó la rebeldía contra la subordinación española, en este periodo encontramos que el texto del filósofo Bentham, Principios de legislación universal y legislación penal (1816/1981), adoptado en nuestro país con propósitos educativos, generó durante más de 50 años el mayor número de debates y controversias entre próceres, legisladores, académicos, eclesiásticos y padres de familia. Este fue un texto de uso obligatorio en la cátedra llamada de legislación civil y penal. De ello da cuenta el Plan General de Estudios, en su decreto 3 de octubre de 1816.

La primera polémica que queremos destacar es que el texto no planteó la relación entre moral y Dios. Esto se debe a que el filósofo-jurista consideraba que la moral no es de Dios, sino consecuencia de las acciones y del gobierno de las instituciones, pues son estas las que procuran felicidad (placer), pero también los males (dolor). En consecuencia, en procesos de formación ciudadana la experiencia y la legislación - gobierno- producen tanto felicidad como dolor. Seguidamente, en el texto se sostenía que son las experiencias las que fortalecen o no los hábitos hacia el bien común, no un estado innato. Recordemos que para entonces se sostenía que existía una condición natural que nos hacia sensibles a la realización de actos benevolentes/maldadosos; justos/injustos. Al contrario, para Bentham los sentimientos de simpatía, dolor, felicidad, entre otros, no están "depositados en un cuerpo". Estos expresan y comunican nuestras experiencias en la vida pública y privada.

Estos debates se reflejaron en normativas institucionales y en los textos escolares hasta inicios de 1900. En este periodo encontramos legislaciones que indicaban cuáles textos de educación moral se debían emplear en las instituciones educativas. En estos se privilegió el método del diálogo por ser con- siderado sencillo y de fácil comprensión para niños y niñas. También se incorporaron cuentos, poemas y, especialmente, apólogos.

En el texto Educación de la infancia, lecciones de moral y urbanidad para la infancia (1846), los diálogos se acompañaron de cuentos relacionados con situaciones de la vida cotidiana, con héroes que participaban en las guerras griegas y romanas y con los enfrentamientos entre piratas. También fueron objeto de relato las guerras acaecidas en la Nueva Granada. Paulatinamente, en este texto se incorporan los sentimientos asociados a la virtud y la moral. Entre estos, la solidaridad frente a quienes se encuentran en situaciones de indigencia, pobreza $\mathrm{u}$ orfandad. Los sentimientos que tienen mayor presencia en este texto se relacionan con el amor y la repugnancia. El sentimiento de amor aparece en relaciones de sometimiento entre padre/hijo; adulto/ niño; ciudadanos/Dios. Este sentimiento, que es propio de los seres humanos -innatismo-, también se vinculó con situaciones de poder y jerarquía en las cuales por amor debemos ser subordinados:

$$
\begin{gathered}
\text { Con humildad profunda } \\
\text { al padre cariñoso } \\
\text { irá respetuoso } \\
\text { las manos a besar; } \\
\text { que el padre es en la tierra } \\
\text { imágen del Eterno } \\
\text { y el hijo bueno y tierno } \\
\text { en él ha de adorar. }(1846, \text { p. } 4)
\end{gathered}
$$

En cuanto al sentimiento de repugnancia, este se asoció al carácter imperfecto de los seres humanos que nos hace tener vicios. Por ello, se propuso una educación centrada en la adquisición de hábitos de urbanidad e higiene. El asco es la expresión contraria de los buenos hábitos, la urbanidad es el modo correcto de control de las emociones negativas y el vínculo perfecto con los otros, pues es señal de civilización, es decir, de agrado y complacencia con los demás. Esta anatomía del asco y la repugnancia se encarna en el cuerpo, aquel que no goza de aseo, limpieza, buenos modales y decoro en la mesa y en la sociedad: 
Universidad Pedagógica Nacional

Facultad de Humanidades

¿No tembláis cuando veis que os acerca una mano asquerosa?: Tened pues cuidado de no causar a los demás tan repugnancia: reflexionad que una persona asquerosa es un objeto del cual huye uno lo más pronto que pueda. Sed pues cuidadoso en el aseo y limpieza de todo vuestro cuerpo. (1846, p. 8)

En el texto en mención, la anatomía del asco y la repugnancia fueron objeto de enseñanza, tema en el que se incluyó el estudio de la cortesía, la urbanidad y la política. Para alcanzar la anhelada perfección del hombre y con ello, la convivencia y la civilización, se propuso formar a los hombres en emociones que no denotaran “afeminación” y, a las mujeres, en sentimientos que cultivaran la prudencia y la moderación. La ausencia de estos sentimientos engendraba el sentimiento de repugnancia. Ejemplo de repugnancia son los coqueteos de las mujeres hacia los hombres o el que ellas correspondan a las miradas atrevidas de los varones.

Otra situación que provoca repugnancia es la falta de cultivo del silencio como señal de tolerancia. Retomando un verso de Sófocles se indica: "el silencio es el adorno mas hermoso de una mujer" (1846, p. 121). El cultivo del silencio, por parte de las mujeres, no solo expresa la práctica de discriminación y expresión de sometimiento, expone el grado de distorsión de algunos valores como el de la tolerancia.

Los anteriores objetivos de formación ciudadana se mantienen en el texto Catecismo republicano de instrucción popular, publicado en 1865. Además de continuar con la formación en urbanidad, se fortalece la condición servil de los ciudadanos de Estados Unidos de Colombia; condición que los eleva al estatus de seres bien criados o formados. Se mantiene la idea de una anatomía de la repugnancia y el asco, pero se incorporan los sentimientos de dignidad, honor y respeto al poder civil. Estos últimos sentimientos se cultivan porque el objetivo del texto escolar fue destacar y mantener vivo el recuerdo de los próceres e ilustres mártires que contribuyeron a la fundación de la República. Se excluye de esta formación el azote y el sentimiento de vergüenza pública, es decir, todas aquellas situaciones que señalen al niño como ignorante, incapaz e indigno.

A manera de ilustración, encontramos los siguientes fragmentos del texto:

Uno de los principales deberes del director será imprimir en los niños, desde los principios, el espíritu de honor, de vergüenza i de probidad... Vendrá a ser más eficaz para promover en ellos la aplicación al trabajo aquella corrección o castigo que señale como ignorante, incapaz o indigno de pasar a otra clase; no otro que cause dolor o infamia. Lo mismo que pasa en el corazón del hombre ya formado, sucede por lo común en el del niño: el rigor más le exaspera que le corrige. (1865, p. 9)

Para las correcciones por falta de aplicación, poco adelanto en su clase; i otras que nazcan del fondo de la misma enseñanza, bastarán las sérias razones del director, y que los culpables observen que distingue a aquellos que cumplen mejor con sus deberes, von las expresiones que denoten cariño y agrado, ya ocupándolos en tomar lecciones i correjir planas [...]. $(1865, \text { p. } 10)^{6}$

\section{¿Qué hay de nuevo hoy?}

En las entrevistas a los miembros de la comunidad educativa se encontró el sentimiento de indignación como expresión búsqueda de justicia. Este sentimiento se asoció en estudiantes y padres de familia de todos los departamentos con la promoción de acciones colectivas de resistencia frente a situaciones de violación de derechos fundamentales como los relacionados con el conflicto armado colombiano. Esto evidenció comprensión frente al daño que producen los hechos de violencia y reconocimiento del impacto de este tipo de acciones en la sociedad civil y en el entramado de nuestra cultura democrática.

Los estudiantes expresaron sentirse indignados en sus contextos escolares cuando se presenta la burla hacia un compañero. Sin embargo, este sentimiento de indignación pierde su vínculo con demandas de reclamación de derechos cuando se trata de situaciones de conflicto y violencia en el

6 La ortografía se mantiene del original. 
contexto escolar como las riñas y peleas. Los niños, niñas y jóvenes indicaron que son indiferentes ante situaciones de violencia física presentes en su institución escolar. Esta indiferencia también se encontró en los padres quienes indicaron que frente a las riñas o pelas en su barrio o vereda los miembros de su comunidad son proclives a cualquier modo de solución de las diferencias.

Pero si bien los estudiantes expresaron rechazo ante las situaciones de burla, indicaron que no sienten enojo o disgusto cuando se presentan situaciones de discriminación o rechazo hacia compañeros por su orientación sexual, etnia, clase o situaciones personales, entre otros. Expresar enojo índica preocupación por el otro, lo cual se manifiesta con incomodidad por quien está siendo testigo moral. La expresión de enojo ante el rechazo evidencia que el testigo altera su tranquilidad por sentir que se amenaza o vulnera el bienestar del otro. El enojo moral da lugar a otros sentimientos como la indignación, compasión y solidaridad. La baja manifestación de enojo o disgusto por parte de los estudiantes ante una situación de rechazo muestra la poca valoración hacia las diferencias, es decir, existe una baja perspectiva relacional, ausencia de otredad o de identificación con el otro.

¿Cómo entender que los estudiantes expresan sentimientos de rechazo hacia las situaciones de conflicto armado y burlas entre compañeros, pero no expresen sentimientos de enojo frente al maltrato entre pares o en situaciones en las que se rechazan otras identidades y modos de vivir? Atendiendo a los enunciados de los estudiantes, la burla tiene como propósito herir, poner en ridículo y degradar los atributos constitutivos del sujeto, por ello se convierte en un modo de exclusión subjetiva, cuyo sufrimiento genera hundimiento de la estructura subjetiva de los niños y las niñas. Por su parte, la pelea y la riña, no afecta la subjetividad y socialización política, al contario la perciben como un asunto personal o de círculos restringidos que no tienen afectación colectiva. Asimismo, la discriminación la asumen como un hecho natural, propio de los sujetos, no generalizable. Por ello hay que aprender a defenderse.

Mientras los niños, niñas y jóvenes expresan los sentimientos de enojo e indignación frente a los hechos de violencia generados por el conflicto armado y las situaciones de menosprecio y la burla, los docentes de los cuatro departamentos indicaron que promueven el sentimiento de la amistad en procesos de formación ciudadana. Llama la atención que este sentimiento tenga poco impacto en la solución o preocupación por los otros, tal como lo encontramos en los enunciados de los estudiantes. Las riñas y la discriminación entre iguales denotan, precisamente, fragilidad frente a este tipo de sentimiento - amor-

Adicionalmente, los docentes Indican que no consideran objeto de formación sentimientos como la indignación ante la vulneración de derechos o ante situaciones de exclusión y discriminación. Tampoco es objeto de comprensión situaciones que generen sentimientos de miedo y tristeza frente a la vulneración de derechos, pues estos se consideran replegados a la esfera de lo privado y, por lo tanto, carecen de una deliberación pública. No es objeto de formación en contextos educativos la preocupación por el otro, las prácticas de cuidado o el fortalecimiento de la otredad; estas no son consideradas expresiones de una responsabilidad ética y política.

Los anteriores estigmas frente a las emociones se vinculan con la poca preocupación encontrada por los asuntos relacionados con los derechos humanos. Estos hallazgos indican que los docentes no lo convierten en objeto de estudio o reflexión, aunque la Constitución política lo indique y a pesar de que existe una política pública en Colombia en este tema. El Plan Nacional de Educación en Derechos Humanos (PLANEDH, 2009) propone como principios rectores del mismo, entre otros, la promoción de valores y actitudes favorables hacia los derechos como la exclusión y la discriminación.

Uno de los sentimientos que se encontró en los portadores de la nueva cultura, siguiendo la idea de sucesión de generaciones o narrativas sociales propuesta por Ricoeur, fue el sentimiento de cui- 
Universidad Pedagógica Nacional

Facultad de Humanidades

dado, en particular con los animales y la naturaleza. Aunque esta ética del cuidado no se expresó hacia sus congéneres más cercanos, en particular hacia sus pares académicos. La importancia de desarrollar prácticas de cuidado con los animales y, en general, con todos los seres vivos está relacionada con el derecho que estos tienen a una existencia digna. Nussbaum (2008) sostiene que no solo el animal humano tiene derecho a una vida digna, también los otros animales lo poseen. La protección de la vida animal y ambiental está estrechamente vinculada con nuestra capacidad para preocuparnos y relacionarnos con la totalidad del mundo natural.

\section{Conclusiones}

En la tradición liberal de la ciudadanía se sostiene que los criterios normativos como la búsqueda de la igualdad y la libertad han generado transformaciones ético-políticas. Por su parte, el contractualismo político sostiene que la justicia como equidad promueve reivindicaciones sociales y políticas. En la tradición comunitarista se indica que somos seres sociales y culturales, antes que seres económicos. Así, en cada una de las anteriores tradiciones cívicas, los sentimientos y la misma formación ciudadana ocupan un lugar discreto. Precisamente, este estudio reveló, en su análisis teórico, las limitaciones que tienen los anteriores modelos cívicos en relación con el reconocimiento de los sentimientos como marcos de comprensión de situaciones de vulneración de derechos, modos de subordinación y legitimación del poder.

En su carácter empírico, el propósito del estudio fue comprender "lo que dicen que hacen", en contextos educativos, los portadores de la nueva cultura. Atendiendo a la propuesta de Ricoeur, las sucesiones de generaciones con sus discontinuidades y emergencias nos permitieron develar modos de construcción de las subjetividades, procesos de socialización y construcción de identidades. En otras palabras, se conocieron algunas huellas narrativas, las cuales permitieron conocer la memoria colectiva y, con ello, dar cuenta de algunas narrativas sociales, tal como se indicó en la metodología.
Asimismo, se buscó identificar el grado de valoración que tienen los niños, niñas y jóvenes acerca de las prácticas de imputación y rechazo en situaciones de exclusión y desvalorización social. También se indagó la estima que tienen los miembros de la comunidad educativa acerca del ejercicio ciudadano en círculos éticos próximos - familia, amigos, barrio, entre otros- y en círculos éticos amplios -municipio, departamento y país, entre otros-. Adicionalmente, interesó identificar cómo perciben la resolución de situaciones de vulneración de derechos y de humillación pública.

Podemos señalar que, en contextos formativos, algunos atributos de los sentimientos se han distorsionado hasta configurar procesos de sedimentación referidos a su carácter "ciego" e irracional, propios de la vida privada y del mundo femenino. Esta cartografía hizo posible plantearnos algunos interrogantes, sin perder de vista las tensiones que en estos perviven: ¿quiénes somos?, y ¿cómo hemos construido nuestra narrativa pública acerca de lo ciudadano? Por ello, nos resulta dramático indicar que los resultados tejieron una trama narrativa en la cual los episodios de nuestros antepasados y los del presente se relacionan con luchas de reconocimiento ante situaciones de humillación y menosprecio. Asimismo, identificar que en esta narrativa social predominó la indiferencia, es decir, el sentimiento de apatía ante situaciones contingencia y fragilidad en la vida social y política.

En buena medida, estos hallazgos ilustraron lo "dicho" en las narrativas históricas analizadas, lo que aún se mantiene, así como los actuales "decires acerca de lo que hacemos". En las narrativas históricas y en las presentes se encontró el sentimiento de indignación como fuente de resistencia, criterio de vindicación de derechos y búsqueda de justicia ante las victimas (justicia anamnética). En las narrativas de los nuevos portadores de la cultura se encontró una preocupación de los miembros de la comunidad educativa por la ética animal. Así, los sentimientos de dolor y sufrimiento orientaron sus marcos de preocupación por otros seres vivos. Adicionalmente, estos "decires y haceres" hicieron posible interpretar 
la manera en que hemos construido la noción de lo público o nuestros modos de estar juntos. Otro aporte fue develar los modos de construcción de nuestras subjetividades y procesos de socialización. Como resultado tenemos que abundaron narrativas individuales -individuación-. Escasamente, se encontraron narrativas referidas al "nosotros" y no estuvieron presentes narrativas acerca de "los otros".

Por ello, el relato de la otredad estuvo plegado a la narrativa "ese es su problema". Esto permitió entender por qué las luchas de reconocimiento en situación de daño moral y político no tienen trayectorias colectivas, sino individuales. Con estos resultados recobra importancia la metáfora de Levinás (2000) acerca del rostro del vulnerable o indefenso representada en las figuras de "la viuda, el huérfano, la extranjero". Estas metáforas permiten ratificar nuestra propuesta orientada a señalar que en procesos de formación es mejor buscar el humanismo. Los sentimientos morales y políticos pueden aportar en este propósito. Se concluye que es necesario en procesos de formación ciudadana socavar la esperanza normativa puesta en el entendimiento jurídico de la convivencia porque instala los relatos del infractor, de la sanción y de las faltas disciplinarias como orientadores de nuestras prácticas ciudadanas.

\section{Referencias}

Bentham, J. (1981). Principios de legislación universal y legislación penal.Madrid: Editora Nacional.

Fernández De Sotomayor, J. (1820). Catecismo o instrucción popular. Bogotá: Editorial Kelly.

Guerra, M. (2012). Género, migraciones y ciudadanía. Expandiendo la agenda feminista de investigación. Revista Dilemata, año 4, número 14, p.p. 1-4.

Heller, A. (2004). Teoría de los sentimientos. Barcelona: Coyoacán.

Honneth, A. (1997). La lucha por el reconocimiento. Barcelona: Crítica.

Honneth, A. (2009). Crítica del agravio moral, patologías de la sociedad contemporánea. Buenos Aires: Fondo de Cultura Económico.

Honneth, A (2010). Reconocimiento y menosprecio sobre la fundamentación normativa de una teoría social. Buenos Aires: Katz.
Honneth, A (2011). La sociedad del desprecio. Madrid: Trotta.

Hume, D. (1989). Las normas del gusto y otros ensayos. Barcelona: Península.

Hume, D. (1990). Disertación sobre las pasiones y otros ensayos morales. Barcelona: Anthropos.

Hume, D. (1992). Tratado sobre la naturaleza humana. Madrid: Tecnos.

Hume, D. (2006). Investigación sobre los principios de la moral. Madrid: Alianza.

Hutchenson, F. (1999). Escritos sobre la idea de virtud y sentido moral. Madrid: Centro de estudios políticos y constitucionales.

Kant, I. (1785/1989). Fundamentación de la metafísica de las costumbres. Madrid: Espasa-Calpe.

Kohlberg, L. (1992). Psicología del desarrollo moral. Bilbao: Biblioteca de Psicología Desclée de Brouwer.

Levinás, E. (2000). Ética e infinito. Madrid: Machado Libros S.A.

Nussbaum, M. (1995). La fragilidad del bien Fortuna y ética en la tragedia y la filosofía griega. Madrid: Visor.

Nussbaum, M. (1997). Justicia poética, la imaginación literaria y la vida pública. Barcelona: Andrés Bello.

Nussbaum, M. (2003). La terapia del deseo. Teoría y práctica en la ética helenística. Barcelona: Paidós.

Nussbaum, M. (2006). El ocultamiento de los humanos: repugnancia, vergüenza y ley. Buenos Aires: Katz.

Nussbaum, M. (2008). Paisajes del pensamiento. Barcelona: Paidós.

Piaget J. (1932/1977). El criterio moral en el Niño. Barcelona: Editorial Fontanela.

Pinzón, C. (1865). Catecismo republicano. Instrucción popular. Bogotá: Mosaico.

Provincia de Bogotá, (1846). Educación de la infancia. Lecciones de moral, virtud y urbanidad. Bogotá: Lozada.

Reyes Mate, M. (1991). La razón de los vencidos. Barcelona: Anthropos.

Ricoeur, P. (2003). Historia y narratividad. Barcelona: Paidós.

Rousseau, J. (1762/1993). Emilio o de la educación. México: Porrúa.

Smith, A. (1996). La teoría de los sentimientos morales. Madrid: Alianza.

Strawson, P. (1995). Libertad y resentimiento. Barcelona: Paidós. 